\title{
Thyroid Dysfunction And Pregnancy Outcome
}

\author{
Dr. Firdushi Begum \\ Department Of Biochemistry, Gauhati Medical College \& Hospital, Guwahati, India
}

\begin{abstract}
Several studies conducted across the globe have reported a high prevalence of thyroid disorders in pregnant women. However evidence relating to adverse fetal and pregnancy consequences of maternal thyroid disorders are less well defined and not consistent. This study was thus conducted to find out the prevalence of thyroid disorders in pregnant ladies and to evaluate the adverse pregnancy outcomes in pregnant women with such disorders. This study was conducted in the Central Clinical Laboratory,of Gauhati Medical College \& Hospital. Records of TSH reports of samples received from the obstetrics ward and the labour room were maintained and analysed. Follow up of all the cases included in the study was done with regards to fetal and pregnancy outcome with the help of labour room records.During the 1 year period of study 9117 samples were received. Of them 1671 (18.33\%) were found to be hypothyroid and 137(1.5\%) hyperthyroid. Pre-eclampsia was the most common adverse outcome observed in 20.83\% of hypothyroid ladies as compared to $9.1 \%$ in ladies with normal TSH levels. Other adverse outcome was preterm birth in $14.8 \%$, low birth weight $17.14 \%$ and fetal death in $3.89 \%$ of hypothyroid cases. In pregnant ladies with hyperthyroidism significantly high percentage of adverse outcome was also noted. Preeclampsia 15.33\%, preterm delivery 10.21\%, low birth weight $33.06 \%$, and fetal death $2.19 \%$.The findings of this study are in accordance with those of previous studies which have reported high incidence of adverse outcome in pregnant ladies with thyroid disorders. Considering the findings of this and other similar studies it is highly appropriate to consider routine screening of pregnant ladies with TSH test so that thyroid disorders can be diagnosed early in pregnancy and adequately treated to avoid the adverse consequences.
\end{abstract}

Keywords: Free thyroxine, Hypothyroid, Hyperthyroid, Preeclampsia, Thyroid stimulating hormone

\section{Introduction}

Thyroid physiology undergoes a significant change during pregnancy [1]. Various factors like elevated oestrogen and human chorionic gonadotropin (hCG), increase in thyroxine binding globulin, increase in glomerular filtration rate resulting in increased renal loss of iodine bring about these changes. Change in thyroid physiology is mainly to meet the increasing demand of maternal thyroid hormones, for the development of the foetus, mainly that of the Central Nervous System. As hCG is structurally similar to TSH, so the increase in hCG level in $1^{\text {st }}$ trimester causes a transient increase in FT4 and therefore subsequent TSH suppression [2]. Also estrogen stimulation results in increased synthesis of Thyroxine Binding Globulin, which is the thyroid hormone transport protein resulting in increase in thyroxine(TT4) levels [3]. Tri-iodothyronine $\left(\mathrm{TT}_{3}\right)$ and $\mathrm{TT}_{4}$ reach a concentration of $30-100 \%$ of prepregnancy levels in the $1^{\text {st }}$ trimester. Changes in the free hormone levels is however controversial. The fetal thyroid gland begin synthesizing thryoid hormones only after 14 weeks of gestation [4].

Biochemical profiling of thyroid hormones and Thyroid stimulating hormone(TSH), is the cornerstone in confirming the diagnosis of thyroid disorders [5]. Taking into account the normal physiological changes of thyroid hormones during pregnancy, evaluation of results require trimester specific reference range. References ranges recommended by the American Thyroid Association have been used in this study to classify the cases into Euthyroid, Hypothyroid and Hyperthyroid. According to it $0.3-3.0 \mathrm{mU} / \mathrm{L}$ is the normal TSH range in $3^{\text {rd }}$ trimester [6].

Thyroid disorders are prevalent in women of child bearing age and for this reason commonly present in pregnancy and puerperium [7]. Hyperthyroidism occurs in 2/1000 pregnancies, $85 \%$ of them being Grave's hyperthyroidism due to thyroid stimulation by thyrotropin receptor antibodies [8]. The prevalence of Overt Hypothyroidism is estimated to be between 0.3- 0.5\% [9] and Subclinical Hypothyroidism around 2-5\% [10]. Maternal and fetal thyroid insufficiency has been found to cause neurologic impairment and mental retardation in the infant [11,12]. Apart from its effect on the neurological development of the child, hypothyroidism has been found to increase the risk of miscarriage, pregnancy induced hypertension, preeclampsia, anemia, placental abruption, preterm delivery, low birth weight of baby, fetal death and post-partum hemorrhage [13,14]. However when adequately treated these maternal and fetal complications were seen to be averted [15].

As thyroid disorders have been found to be very much prevalent in pregnant ladies and are aggresively treated with high doses of replacement therapy, this prospective study was designed to find out the

(i) prevalence of thyroid disorders in pregnant ladies and

(ii) to evaluate the incidence of adverse pregnancy outcomes in pregnant women with such disorders. 


\section{Materials And Methods}

2.1 Study Design: This study was designed as a prospective observational study to be conducted in Biochemistry Section of Central Clinical Laboratory of Gauhati Medical College \& Hospital, for a period of 1 year from July 2015 to June 2016.

2.2 Data Collection: Samples received in the biochemistry section of Central Clinical Laboratory from the obstetrics ward, labour room and the observation room of O \& G department, having request for TSH test were centrifuged promptly and processed within 2 hours of collection. The TSH reports thus generated were analysed and recorded on a daily basis. Particulars regarding the patients name, age, sex, location was collected from the requisition form sent to the laboratory along with the blood sample.

2.3 Sample Analysis: Vitros TSH test was done using vitros TSH reagent and calibrator in Vitros 5600 Integrated System and EciQ Immunodiagnostic System An immunometric immunoassay technique is used which involves the simultaneous reaction of TSH present in the sample with a biotinylated antibody and a horse radish peroxidase (HRP) labeled antibody conjugate. The antigen-antibody complex is captured by streptavidin on the wells. The bound HRP conjugate is measured by a luminescent reaction. Calibration of the reagent was done every 28 days and both Internal and External Quality Controls were run on a regular basis to ensure the accuracy of the test results.

On the basis of the reports, the thyroid status was defined as follows:

Euthyroid : TSH $-0.3-3.0 \mathrm{mU} / \mathrm{L}$

Hypothyroid : TSH $>3.0 \mathrm{mU} / \mathrm{L}$

Hyperthyroid : TSH $<0.3 \mathrm{mU} / \mathrm{L}$

2.4 Patient Follow up: Information on the outcome of pregnancy like preeclampsia, mode of delivery, birth weight of the baby, preterm birth and other details of delivery was collected from hospital records and recorded in the "delivery details" section of the questionnaire.

Pre-eclampsia was defined as new onset hypertension after 20 weeks of gestation with proteinuria. Low birth weight was defined as babies born with birth weight less than $2.5 \mathrm{Kg}$. Preterm birth was defined as babies born before 37 completed weeks of gestation.

2.5 Statistical analysis: The data was expressed as number, $\mathrm{n}(\%)$. Statistical analysis was carried out by chisquare test by using software "GraphPad Instat version 3". P- value $<0.05$ was considered to be statistically significant.

\section{Results \& Observation}

During the 1 year period of study 9117 samples were received from the labour room, observation room and obstetrics ward for TSH estimation. Of them 1671 (18.33\%) were found to be hypothyroid and $137(1.5 \%)$ hyperthyroid.

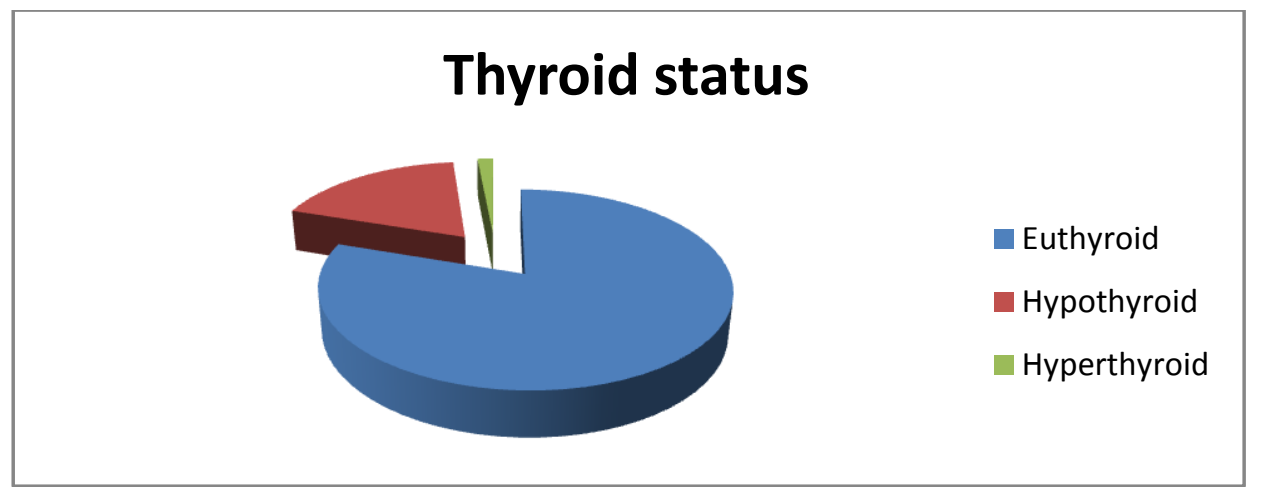

Fig 1 : Prevalence of thyroid disorders.

Table 1 : Adverse pregnancy outcome according to thyroid status.

\begin{tabular}{|l|l|l|l|}
\hline Adverse Pregnancy Outcome & $\begin{array}{l}\text { Euthyroid(N=7309) } \\
\mathrm{n}(\%)\end{array}$ & $\begin{array}{l}\text { Hypothyroid (N=1671) } \\
\mathrm{n}(\%)\end{array}$ & $\begin{array}{l}\text { Hyperthyroid } \\
(\mathrm{N}=137) \\
\mathrm{n}(\%)\end{array}$ \\
\hline Pre-eclampsia & $665(9.1)$ & $348(20.83)^{* *}$ & $21(15.33)^{*}$ \\
\hline Preterm delivery & $314(4.3)$ & $247(14.8)^{* *}$ & $14(10.21)^{* *}$ \\
\hline Caeserian delivery & $1316(18)$ & $570(34.11)^{* *}$ & $40(29)^{* *}$ \\
\hline Low Birth Weight & $555(7.6)$ & $286(17.14)^{* *}$ & $45(33.06)^{* *}$ \\
\hline Foetal death & $44(0.6)$ & $65(3.89)^{* *}$ & $3(2.19)$ \\
\hline
\end{tabular}

$* *-\mathrm{P}<.0001, * \mathrm{P}<.05$ 


\section{Discussion}

This prospective observational study was done in Gauhati Medical College \& Hospital, which is a tertiary care referral hospital. Approximately forty deliveries are conducted everyday in this hospital. The blood samples for TSH estimation from the obstetrics ward, observation room and labour room are sent to the Central Clinical laboratory. There are many studies which have shown that thyroid dysfunction during pregnancy results in adverse pregnancy outcome like preeclampsia, preterm delivery, delivery of low birth weight baby, and intrauterine foetal death $[13,14,16]$. This prospective study was designed to verify the findings of previous studies regarding adverse pregnancy outcome in pregnant ladies with thyroid dysfunction. In the one year period of study 9117 samples of pregnant ladies were received for TSH estimation. Of these $18.33 \%$ were found to be hypothyroid and $1.5 \%$ were hyperthyroid. This finding of high prevalence of hypothyroidism in pregnant ladies is in accordance with other similar studies by Sahu M et al and others [13,17,18].

Proceeding on to analysis of the findings related to the outcome of pregnancy, it was observed that adverse outcomes were more in pregnant ladies with abnormal TSH levels as compared to those with normal levels. Pre-eclampsia was the most common adverse outcome followed by low birth weight of the baby and pre-term delivery . Hypothyroidism has been listed as one of the causes of high blood pressure, which is one of the factors of preeclampsia [19]. In preeclampsia there is decrease production of estrogen resulting in decrease levels of thyroxine binding globulin and in turn low levels of thyroid hormones [20]. Pre-eclampsia was observed in $20.83 \%$ of hypothyroid ladies as compared to $9.1 \%$ in ladies with normal TSH levels. This is a significant observation with p-value $<.001$. The incidence of pre-eclampsia was also found to be significantly high in those with low TSH levels. The findings of the present study are in accordance with those of previous researchers. Other way round there are studies which have gone to show that women complicated with preeclampsia have high incidence of hypothyroidism that might correlate with the severity of pre-eclampsia [2124].

Pre-term delivery defined as birth before 37 weeks of gestation, is an important cause of perinatal mortality and morbidity. It was found in $14.8 \%$ of hypothyroid and $10.21 \%$ of hyperthyroid pregnancies, a significant finding with $\mathrm{p}<.001$,compared to $4.3 \%$ of euthyroid pregnant ladies. Negro et al has reported the pre-term delivery as $22.4 \%$ for euthyroid women who were TPO +ve but did not receive any treatment with levothyroxine as compared to the low incidence $(8.2 \%)$, in euthyroid women who were TPO-ve [25]. There are similar observations made in other studies, whereas Antolic et al reported no difference in preterm delivery between women with thyroid dysfunction and euthroid controls but significant difference in very pre-term delivery(VPTD which is before 32 weeks) between the two groups, $2.7 \%$ vs $1.5 \%$, p value $<0.05$ [26]. In the present study 14 of the 137 cases of pregnant hyperthyroid had a pre-term delivery giving us a percentage of 10.21 .

$34.11 \%$ and $29 \%$ of pregnant hypothyroid and hyperthyroid ladies respectively delivered by caeserian section as compared to $18 \%$ of pregnant ladies with normal TSH levels. Allan et al [27] and Benhadi et al [28] showed that high TSH levels were significantly associated with higher frequency of still birth. In the current study $3.89 \%$ of hypothyroid and $2.19 \%$ of hyperthyroid ladies delivered a stillborn baby. It has been suggested that hypothyroidism may exert irreversible effects on the fetus and placenta in early pregnancy which impairs their subsequent ability to tolerate stress, thereby increasing the incidence of foetal distress and still birth.

The findings of this study are in accordance with those of other similar studies done to study the incidence of adverse outcome in pregnant ladies with thyroid disorders. The incidence however varied with regard to different adverse outcomes like pre-eclampsia, preterm delivery, low bith weight and intrauterine foetal death. But all the studies reported a greater percentage of adverse outcome in cases of overt thyroid disorders rather than the subclinical disorders. The major drawback of this study is that as as it is based on the TSH level the cases could not be grouped into overt and subclinical.

\section{Conclusion}

This study concludes that the prevalence of thyroid dysfunction is high among pregnant ladies, majority of them being hypothyroid. And considering the high incidence of adverse outcome, it is advisable to routinely screen pregnant ladies with the help of TSH test, for presence of thyroid disorders, and to adequately treat them with replacement therapy.

\section{References}

[1]. Glinoer D. . The regulation of thyroid function in pregnancy: pathways of endocrine adaptation from physiology to pathology. Endocr Rev, 18, 1997,404-33.

[2]. Brent GA. Maternal thyroid function: interpretation of thyroid function tests in pregnancy. Clin Obstet Gynecol,40, 1997,3-15.

[3]. Sahay RK, Nagesh VS. Hypothyroidism in pregnancy. Indian J Endocr Metab,16,2012,364-70.

[4]. Ain KB, Mori Y, Refetoff S.Reduced clearance rate of thyroxine binding globulin(TBG) with increased sialylation. A mechanism for estrogen -induced elevation of serum TBG concentration. J Clin Endocrinol Metab ,65,1987,689-702.

[5]. Jayakumar RV. Elevated TSH levels in elderly -Physiologic or Pathologic?Medicine Update,22,2012,315-316. 
[6]. Stagnaro- Green A, Abalovich M, Alexander E, et al. Guidelines of the American Thyroid Association for the diagnosis and management of thyroid disease during pregnancy and post partum. Thyroid. 21(10),2011,1081-125.

[7]. Krassas GE, Poppe K, Glinoer D. Thyroid function and human reproductive health. Endocr Rev 31,2010,702-705.

[8]. Marx H, Amin P, Lazarus JH. Hyperthyroidism and pregnancy. BMJ ,22,2008,663-7.

[9]. Abalovich M, Gutierrez S, Alcaraz G et al. Overt and Subclinical hypothyroidism complicating pregnancy. Thyroid,12, $2002,63$.

[10]. Woeber KA. Subclinical thyroid dysfunction . Arch Intern Med ,157,1997,1065-8.

[11]. Xue-Yi C, Xin Min J, Zhi Hong D, Rakeman MA, Ming- Li Z, O’Donnell K et al. Timing of vulnerability of the brain to iodine deficiency in endemic cretinism. N Engl J Med ,331,1994,1739-44.

[12]. Delong GR, Stanbury JB, Fierro- Benitez R. Neurological signs in congenital iodine- deficiency disorder. Dev Med Child Neurol ,27,1985, 317-24.

[13]. Casey BM, Dashe JS, Wells CE et al. Subclinical hypothyroidism and pregnancy outcomes . Obstet Gynecol,105, 2005,239-45.

[14]. Negro R. Thyroid insufficiency during pregnancy : complications and implications for screening. Expert Rev.Endocrinol. Metab ,32,2008,1-10.

[15]. Verga U, Bergamaschi S, Cortelazzi D, Ronzoni S, Marconi A, Beck-Peccoz P. Adjustment of L-T4 substitute therapy in pregnant women with subclinical, overt or post-ablative hypothyroidism. Clinical Endocrinology,70, 2009, 798-802.

[16]. So LB, Mandel SJ. Thyroid disorders during pregnancy. Endocrinol Metab Clin North Am,35, 2006,117-36.

[17]. Sahu $\mathrm{M}$ et al. Overt and subclinical thyroid dysfunction among Indian pregnant women and its effect on maternal and fetal outcome . Archives of gynecology and obstetrics,281(2), 2010,215-220.

[18]. Klein RZ, Haddow JE, Faix JD, Brown RS, Hermos RJ, Pulkkinen A, et al. Prevalence of thyroid deficiency in pregnant women. Clin Endocrinol (Oxf),35,1991,41-6.

[19]. Endo T, Komiya I, Tsukui T. Re-evaluation of a possible high incidence of hypertensive in hypothyroid patients. Am Heart J,98, 1979,684-8

[20]. Kaye E, Sahin Y, Ozkececi Z, Pasaoglu H. Relation between birth weight and thyroid function in pre-eclampsia -eclampsia. Gynecol Obstet invest,37, 1994,30-3.

[21]. Lao TT, Chin RKH, Swaminathan R, Lam YM. Maternal thyroid hormones and outcome of preeclamptic pregnancies. Br J Obstet Gynecol,97, 1990,71-4.

[22]. Osathanondh R, Tulchinsky D, Chopra IJ. Total and free thyroxine and triiodothyronine in normal and complicated pregnancy. J Clin Endocrinol Metab,42,1976,98-104.

[23]. Tolino A, De Concilus B, Montemagno U. Thyroid hormones in human pregnancy. Acta Obstet Gynecol Scan,64, 1985,557-9.

[24]. Khaliq F, Singhal U, Arshad Z, Hossain MM. Thyroid functions in pre-eclampsia and its correlation with maternal age, parity, severity of blood pressure and serum albumin. Indian J Physiol Pharmacol,43,1999,193-8.

[25]. Negro R, Formoso G, Mangieri, Pezzarossa A, Dazzi D, Hassan H. Levothyroxine treatment in euthyroid pregnant women with autoimmune thyroid disease: effects on obstetrical complications. J Clin Endocrinol Metab,91, 2006,2587-2591.

[26]. Antolic B, Gersak K, Verdenik I, Novak-Antolic Z. Adverse effects of thyroid dysfunction on pregnancy and pregnancy outcome: epidemiologic study in Slovenia. J Matern Fetal Neonatal Med,19,2006,651-54

[27]. Allan WC, Haddow JE, Palomaki GE et al. Maternal thyroid deficiency and pregnancy complications: implications for population sceening. J Med Screen ,7,2000,127-30.

[28]. Benhadi N, Wiersinga WM, Reitsma JB et al. Higher maternal TSH levels in pregnancy are associated with increased risk for miscarriage, fetal or neonatal death. Eur J Endocrinol,160(6), 2009,985-91. 